\title{
VARIABILIDADE ESPECTRAL DE VAZÃO DE RIOS BRASILEIROS
}

\author{
Simone Erotildes Teleginsk Ferraz ${ }^{1, *}$, Andrea de Oliveira Cardoso ${ }^{2}$, Caluan Rodrigues \\ Capozzoli $^{2}$ \\ ${ }^{1}$ Universidade Federal de Santa Maria, RS, Brasil \\ ${ }^{2}$ Universidade Federal do ABC, SP, Brasil \\ *simonetfe@gmail.com
}

\section{INTRODUÇÃO}

A hidrografia do Brasil é caracterizada pela quantidade e extensão das bacias hidrográficas que conferem ao país uma das mais importantes reservas de água doce do planeta. Além da utilização para o consumo humano, no Brasil os recursos hídricos estão diretamente ligados com importantes atividades econômicas como a agricultura e a geração de energia elétrica. A variabilidade da vazão de rios é determinada por fatores relacionados à interação entre a precipitação e a fisiologia da bacia (Tucci, 2009), refletindo a importância da variabilidade espacial da precipitação para os padrões de vazão de rios.

É conhecido que as vazões de rios sofrem influências remotas de fenômenos climáticos, via precipitação. Marengo et al. (2012) avaliam extremos secos e chuvosos na região amazônica usando níveis e descarga de rios como indicadores de impactos. $\mathrm{O}$ aumento (diminuição) de extremos de vazão na região das bacias do Paraguai e Uruguai (Brasil central) está relacionado com a ocorrência de eventos El Niño (La Niña) (Tedeschi e Grimm, 2008).

Cardoso e Cataldi (2012) observaram que a vazão de rios brasileiros possui relações significativas com diferentes padrões climáticos e de teleconexões, com destaque para a correlação com os padrões de variabilidade de mais baixa frequência, como ODP, Oscilação Multidecadal do Atlântico e o ENOS. Foi destacada a atuação de padrões específicos em meses preferenciais, possivelmente devido à sazonalidade de cada local e dos principais mecanismos atuantes em cada região.

Devido a grande variedade de mecanismos que influenciam o padrão de chuvas sobre o Brasil e, consequentemente, impactam o regime de vazão dos rios, este estudo objetiva identificar as principais variabilidades presentes nas séries de vazão. 


\section{DADOS E METODOLOGIA}

Foram utilizados dados históricos mensais de vazão natural em rios brasileiros, de 163 postos em locais de aproveitamentos hidroelétricos, disponibilizados pelo Operador Nacional do Sistema Elétrico.

Também foram utilizadas séries dos seguintes índices climáticos: Oscilação Multidecadal do Atlântico (AMO); Anomalia de TSM no Atlântico tropical sul (TSA); Oscilação Decadal do Pacífico (PDO); Anomalia de TSM na área Niño 3.4 (N3.4). O período de estudo foi de 1979 a 2008.

Para identificar os padrões de variabilidade presentes nos dados de mensais de vazão de rios nas diferentes bacias brasileiras, foi utilizada a análise de componentes principais. Posteriormente, correlacionou-se as séries temporais dos modos com os históricos dos índices climáticos citados acima.

Com o objetivo de identificar os ciclos mais significativos de cada modo de vazão de rios, foi calculada a densidade espectral de potências das séries temporais dos principais modos, usando diferentes janelas espectrais (lags), o que permite detectar ciclos com diferentes frequências.

\section{RESULTADOS}

O padrão espacial do primeiro modo (não mostrado), com variância explicada de $34.4 \%$, destaca a região central da Bacia do Paraná principalmente entre o norte do Estado de São Paulo, leste do Mato Grosso do Sul e norte de Minas Gerais. A série temporal apresenta ciclos interanuais com um forte pico no ano de 1983 (ano de El Niño forte). Também se observa variações de mais baixa frequência na escala decadal, principalmente antes da década de 1970, que pode estar relacionada com a PDO, sendo que a partir desse período há predomínio da variabilidade interanual.

Diante das variações capturadas pelo primeiro modo de vazão de rios, há indicativos de que a PDO positiva pode atuar de forma construtiva para a ocorrência de El Niño e deste modo direta ou indiretamente afetar a precipitação e consequentemente a vazão dos rios, com maior efeito sobre a Bacia do Paraná. 
Resultados da análise espectral (tabela 1), para os diversos lags, indicaram a presença de picos significativos na escala semianual (4 e 5 meses), sendo também identificados picos próximos as escalas interanual e decadal (11.7 e 96 meses). Esses picos podem estar associados aos fenômenos ENOS, na escala interanual, às oscilações decadal e multidecadal (PDO e AMO, respectivamente) e as variabilidades sazonais das anomalias no Atlântico tropical sul, via TSA, conforme capturado pelas análises de correlações, com valores de coeficientes de 0,13 (N34), 0,23 (PDO), -0,22 (AMO) e -0,31 (TSA).

Comparando com a tabela 2 (picos significativos dos índices) é possível verificar que os picos espectrais do modo 1 mais significativos correspondem ao mesmo período dos índices AMO, N34, TSA e PDO, o que concorda com o resultado das correlações.

Tabela 1: picos espectrais significativos do $1^{\circ}$ modo.

\begin{tabular}{|c|c|c|}
\hline & Lag (meses) & Picos espectrais (meses) \\
\hline Modo 1 & 120 & $5 ; 4.1$ \\
\hline Modo 1 & 480 & $96 ; 11.7 ; 5.1 ; 3.3$ \\
\hline
\end{tabular}

Tabela 2: picos espectrais significativos dos índices climáticos.

\begin{tabular}{|l|l|}
\hline & Picos espectrais (meses) \\
\hline AMO & $100 ; 44 ; 12$ \\
\hline N34 & $120 ; 48 ; 30 ; 26 ; 17$ \\
\hline PDO & $80 ; 15 ; 12 ; 7$ \\
\hline TSA & $120 ; 80 ; 30 ; 17 ; 10$ \\
\hline
\end{tabular}

\section{CONCLUSÃO}

A variabilidade climática é um fator condicionante para variações nos recursos hídricos brasileiro, que apresenta grande variabilidade espacial e temporal dada às características climáticas ao logo do território e as fisiologias das bacias. O primeiro modo destaca a 
importância das variabilidades na TSM do Pacífico e Atlântico, tropical e norte, sobre as variações na vazão de rios brasileiros. As análises evidenciam a modulação da PDO sobre o ENSO e o impacto na vazão de rios, de mesmo sinal que a fase dessa oscilação, sobre a maior parte do país, principalmente na Bacia do Paraná. O Atlântico influencia tanto em escala multidecadal (AMO) como em mais alta frequência, através das variações nas anomalias de TSM sobre a faixa tropical sul (TSA).

\section{AGRADECIMENTOS}

Ao CNPq (nº 480683/2010-7, Bolsa Pq 304688/2012-6) e a FAPERGS (PRONEM).

\section{REFERÊNCIAS}

CARDOSO, A. O.; CATALDI, M. Relações de índices climáticos e vazão de rios no Brasil. In: Anais XVII CBMET, 2012.

MARENGO, J. A.; Borma, L. S.; Rodriguez, D. A.; Pinho, P.; Soares, W. R. e Alves, L. M. Recent extremes of drought and flooding in Amazonia: vulnerabilities and human adaptation. In: American Journal of Climate Change, on line, 2012.

TEDESCHI, R. G.; GRIMM, A. M. Variações significativas de eventos extremos de precipitação e de vazão durante episódios de El Niño e La Niña. In: Anais do XV CBMET, 2008.

TUCCI, C. E. M. Hidrologia: ciência e aplicação. 4 ed. Porto Alegre: Editora da UFRGS/ABRH, 2009, 943 p. 